\title{
Coprostanol in a Sediment Core from the Anoxic Tan-Shui Estuary, Taiwan
}

\author{
Woei-Lih Jeng a and Bor-Cheng Han \\ anstitute of $\mathrm{O}$ ceanography, $\mathrm{N}$ ational Taiwan $U$ niversity, T aipei, Taiwan, \\ Republic of $\mathrm{C}$ hina and ${ }^{\mathrm{b}} \mathrm{S}$ chool of Public $\mathrm{H}$ ealth, Taipei $\mathrm{M}$ edical College, Taipei, \\ Taiwan, Republic of China
}

Received 22 December 1993 and in revised form 7 J uly 1994

Key words: coprostanol; extractable; bound; sediment; diagenesis

\begin{abstract}
A short sediment core with a length of approximately $40 \mathrm{~cm}$ taken from the anoxic Tan-Shui estuary, T aiwan, was analysed for extractable and bound coprostanol ( $5 \beta$-cholestan- $3 \beta$-ol), cholestanol ( $5 \alpha$-cholestan-3 $\beta$-ol) and cholesterol (cholest-5-en-3 $\beta$-ol). Extractable $\Sigma$ coprostanol and cholestanol concentrations exhibit an abrupt change at a depth of about $20 \mathrm{~cm}$, which supposedly marks the time when a sewage treatment plant became operational in the estuary in 1980. The $\Sigma$ coprostanol/cholesterol and cholestanol/cholesterol ratios are comparatively higher in sediment than in the sewage effluent, implying some degree of diagenesis in the extractable phase. Anoxicity must have played a crucial role in the preservation and diagenesis of the sterols. In the upper layer (c. top $20 \mathrm{~cm}$ ), the concentrations of extractable $\Sigma$ coprostanol, normalized to total organic carbon (TOC), increase down the core. Extractable cholestanol exhibits the same trend, but extractable cholesterol shows the opposite trend. This indicates cholesterol reduction to these two stanols. In addition, both bound $\Sigma$ coprostanol/TOC and cholestanol/TOC display a decreasing trend with core depth and no pronounced concentration change at $20 \mathrm{~cm}$ depth. The averages of percent bound sterols are in the following order: cholesterol $>\Sigma$ coprostanol >cholestanol.

(C) 1996 Academic Press Limited
\end{abstract}

\section{Introduction}

Coprostanol ( $5 \beta$-cholestan-3 $\beta$-ol) has been used to trace sewage pollution in various sedimentary environments ( $G$ oodfellow et al., 1977; H atcher \& M cG illivary, 1979; Y de et al., 1982; Brown \& Wade, 1984; Readman et al., 1986; Venkatesan \& K aplan, 1990; LeBlanc et al., 1992). A chronological study of coprostanol concentrations in a dated sediment core has been shown to reflect the true sewage inputs over 160 years ( $M$ uller et al., 1979). C oprostanol will degrade during aerobic wastewater treatment processes (M cC alley et al., 1981). H owever, coprostanol, along with cholesterol (cholest-5-en-3 $\beta$ ol) and cholestanol ( $5 \alpha$-cholestan-3 $\beta$-ol), is quite persistent in anoxic sedimentary environments ( $\mathrm{N}$ ishimura \& K oyama, 1977; Hatcher \& M cG illivary, 1979; M cCalley et al., 1980; Readman et al., 1986; Bartlett, 1987). The hydrogenation of naturally occurring unsaturated sterols may be effected extremely rapidly in contemporary aquatic 


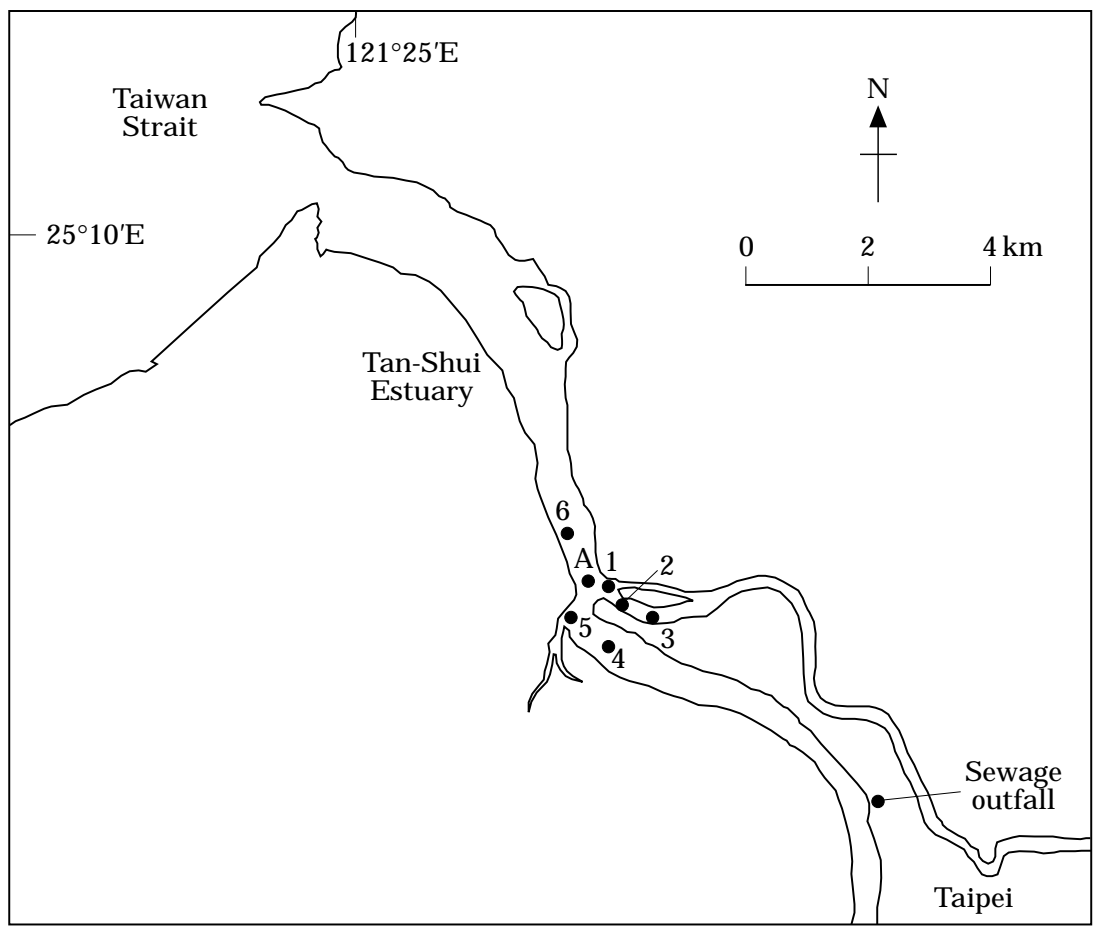

Figure 1. M ap showing the coring sites in the T an-Shui estuary.

sediments (G askell \& E glinton, 1975). Sterol diagenesis has been studied in a bay (L ee et al., 1977), a lake (N ishimura, 1978) and laboratory experiments ( $N$ ishimura, 1982).

The T an-Shui estuary is located on the outskirts of the metropolitan area of T aipei city, with a population of approximately 3 million. T he T an-Shui river carries untreated sewage along its course, and treated sewage effluent has been discharged into the estuary since 1980. High levels of coprostanol have accumulated in the estuary (Jeng \& $\mathrm{H}$ an, 1991). The estuary is very anoxic; dissolved oxygen is virtually zero. A preliminary survey shows that redox potential $\left(E_{h}\right)$ values of the surface sediments range from 0 to $-500 \mathrm{mV}$ approximately. This anoxicity has lasted for a very long period of time which aids in the preservation of coprostanol in sediments. The aim of this study was to investigate the short-term diagenesis of coprostanol, cholestanol and cholesterol in the anoxic environment by analysing their concentrations in the extractable and bound phases.

\section{Experimental}

Sediment cores were taken from the Tan-Shui estuary (Figure 1) using a gravity corer with a $6-\mathrm{cm}$ diameter core barrel. Core $A$ had a length of about $40 \mathrm{~cm}$ and was sectioned at $5-\mathrm{cm}$ intervals from the top for analysing sterols. Cores 1-6 were measured for the downcore variation of $E_{h}$.

For measuring redox potentials, the core liner was drilled with a series of holes (allowing the redox electrode to be inserted into sediment) at $2 \cdot 5-\mathrm{cm}$ intervals along the liner length. Before sampling, the holes were taped with masking tape. Immediately after 
retrieving the core, the masking tape was peeled off the liner, and $\mathrm{E}_{\mathrm{h}}$ was measured in situ with a combined reference $(\mathrm{Ag} / \mathrm{AgCl})$ and platinum electrode from the core top, one hole at a time. The reading was taken after a period of $60 \mathrm{~s}$, to ensure that the electrode had reached a steady potential.

All solvents used were H PLC grade and/or all-glass distilled. All reagents employed were reagent grade.

Each section of C ore A was freeze-dried and extracted with a mixture of benzene and methanol $(1: 1, v / v)$ in a Soxhlet apparatus for $24 \mathrm{~h}$. 1-N onadecanol was added to the extract as an internal standard. T he spiked extract was concentrated and saponified with $0.5 \mathrm{~N}$ methanolic $\mathrm{KOH}$. The neutral lipid was extracted with $\mathrm{n}$-hexane four times. $\mathrm{T}$ he extracted lipid was fractionated by silica gel (deactivated with $5 \%$ water) column chromatography. The less polar lipids were removed by elution with $40 \%$ hexane in chloroform, and the sterol-containing fraction was isolated using $10 \%$ methanol in chloroform.

The extracted sediment residue was subjected to alkaline hydrolysis ( $16 \mathrm{~h}$ ) for releasing bound lipids, followed by filtration, internal standard addition, n-hexane extraction and sterol isolation.

The isolated sterols (both extractable and bound) were derivatized with $\mathrm{NO}$-Bis (trimethylsilyl) acetamide prior to gas chromatography (GC) analysis.

Sterols (as T M S ethers) were analysed by capillary GC and gas chromatography-mass spectrometry (GC-M S). Separations were performed with an H P 5890A gas chromatograph equipped with a flame ionization detector (FID) and a split/splitless capillary column inlet system. An O CI-5 cool on-column injector (SGE, A ustralia) was also fitted in the chromatograph for quantitation. A $30 \mathrm{~m} \times 0.25 \mathrm{~mm}$ i.d., $0.25 \mu \mathrm{m}$ film thickness, SE - 30 bounded-phase fused silica capillary column was used. $\mathrm{H}$ ydrogen was used as the carrier gas. $\mathrm{N}$ itrogen served as the make-up gas. The detector was set at $300{ }^{\circ} \mathrm{C}$. Oven temperature was programmed as follows: (1) $45-90{ }^{\circ} \mathrm{C}$ at $15^{\circ} \mathrm{C} \min ^{-1}$; (2) $90-270{ }^{\circ} \mathrm{C}$ at $3{ }^{\circ} \mathrm{C} \mathrm{min}^{-1}$; (3) $20 \mathrm{~min}$ at $270{ }^{\circ} \mathrm{C}$; (4) $270-280^{\circ} \mathrm{C}$ at $10^{\circ} \mathrm{C} \mathrm{min}^{-1}$; and (5) $20 \mathrm{~min}$ at $280^{\circ} \mathrm{C}$. Identification was made by co-injection with authentic standards. Positive confirmation was done with a Finnigan M AT TSQ-46C GC/M S. All GC traces were recorded by a Shimadzu data processor, Chromatopac C-R6A. Quantitation was achieved by comparison of sample peak areas with the areas of the internal standard. The precision of the method was determined by five replicate analyses of the same sediment sample, and the relative standard deviation was $2 \cdot 1 \%$.

T otal organic carbon was determined by the dichromate acid oxidation method ( $G$ audette et al., 1974) modified by addition of $\mathrm{Ag}_{2} \mathrm{SO}_{4}$ to $\mathrm{H}_{2} \mathrm{SO}_{4}$ at the rate of $15 \mathrm{gl}^{-1}$, with ortho-phenanthroline-ferrous complex used as the indicator. The relative standard deviation of T OC determinations was generally $<1 \%$.

\section{Results and discussion}

Prior to discussing sterols, it is important to know the redox state of the sediment in the estuary. As shown in T able $1, E_{h}$ values are virtually negative and generally in the range between -100 and $-200 \mathrm{mV}$. The general trend of depth profiles is that the $E_{h}$ values decrease with depth in the upper core and fluctuate with depth in the lower core.

For the extractable phase, $\Sigma$ coprostanol and cholestanol concentrations vs. core depth exhibit a large break between Sections 4 and 5 (i.e. at a depth of about $20 \mathrm{~cm}$ ), which indicates an extra large input of coprostanol from sometime in the past to the sampling time (T able 2). This depth supposedly marks the time when a sewage treatment plant 
T ABLE 1. Redox potentials (mV) in sediment cores from the T an-Shui estuary

\begin{tabular}{|c|c|c|c|c|c|c|}
\hline \multirow{2}{*}{$\begin{array}{l}\text { D epth } \\
(\mathrm{cm})\end{array}$} & \multicolumn{6}{|c|}{ Core } \\
\hline & 1 & 2 & 3 & 4 & 5 & 6 \\
\hline $0.0-2 \cdot 5$ & -16 & 4 & 11 & 5 & -30 & -70 \\
\hline $2 \cdot 5-5 \cdot 0$ & -112 & -96 & -7 & -49 & -59 & -95 \\
\hline $5 \cdot 0-7 \cdot 5$ & -142 & -160 & -6 & -77 & -140 & -170 \\
\hline $7 \cdot 5-10 \cdot 0$ & -114 & -180 & -21 & -129 & -152 & -218 \\
\hline $10 \cdot 0-12 \cdot 5$ & -179 & -176 & -41 & -162 & -147 & -194 \\
\hline $12 \cdot 5-15 \cdot 0$ & -209 & -119 & -83 & -169 & -140 & -215 \\
\hline $15 \cdot 0-17 \cdot 5$ & -217 & -172 & -122 & -149 & -222 & -113 \\
\hline $17 \cdot 5-20 \cdot 0$ & -216 & -150 & -139 & -160 & -119 & -152 \\
\hline $20 \cdot 0-22 \cdot 5$ & -148 & -192 & -157 & -133 & -90 & -208 \\
\hline $22 \cdot 5-25 \cdot 0$ & -230 & -161 & -181 & -129 & -171 & -252 \\
\hline $25 \cdot 0-27 \cdot 5$ & -214 & -152 & -120 & -168 & -131 & - \\
\hline $27 \cdot 5-30 \cdot 0$ & -96 & -123 & -134 & -172 & -111 & - \\
\hline $30 \cdot 0-32 \cdot 5$ & -213 & -60 & -163 & -182 & -186 & - \\
\hline $32 \cdot 5-35 \cdot 0$ & -134 & -155 & -81 & -42 & - & - \\
\hline $35 \cdot 0-37 \cdot 5$ & -200 & -171 & -39 & -195 & - & - \\
\hline $37 \cdot 5-40 \cdot 0$ & -125 & -177 & -60 & -58 & - & - \\
\hline $40 \cdot 0-42 \cdot 5$ & -206 & -110 & -108 & -55 & - & - \\
\hline $42 \cdot 5-45 \cdot 0$ & -172 & - & -72 & -96 & - & - \\
\hline $45 \cdot 0-47 \cdot 5$ & -217 & - & -100 & -66 & - & - \\
\hline
\end{tabular}

became operational in 1980, and considerably higher levels of coprostanol began to be deposited in the estuary. This record has been well kept due to anoxicity, which aids in the preservation of coprostanol.

Core A was located not far from the sewage outfall (Figure 1) which was presumably the predominant coprostanol source for this core. The $\Sigma$ coprostanol/cholesterol and cholestanol/cholesterol ratios of the effluent from the sewage outfall were 0.69 and 0.043 , respectively, and those of Core A sediments had averages of 2.19 and 1.43 , respectively ( $T$ able 2 ). The increases in the two ratios are of particular interest. It has been well documented in the literature that there is little decay of coprostanol, cholesterol and cholestanol in anaerobic sediments ( $\mathrm{N}$ ishimura \& Koyama, 1977; Hatcher \& M cGillivary, 1979; M cCalley et al., 1980; Readman et al., 1986; Bartlett, 1987). F urthermore, cholesterol can be transformed into coprostanol and cholestanol in a reducing environment ( $G$ askell $\&$ Eglinton, 1975). The present result with comparatively higher stanol/stenol ratios implies rapid hydrogenation of cholesterol, which could lead to the conversion of cholesterol into coprostanol and cholestanol in the reducing environment.

Since grain size has a significant effect on the distribution of organic compounds in sediment, concentrations of molecular data are usually normalized to T OC (Jeng $\& \mathrm{H}$ an, 1991; L eB lanc et al., 1992; Jasper \& G agosian, 1993); variation trends and/or meaningful results can readily be obtained. $\Sigma$ Coprostanol, cholestanol and cholesterol concentrations are normalized to TOC, and their variations, both extractable and bound, vs. depth are given in Figures 2-4. It can be seen that the concentrations of extractable $\Sigma$ coprostanol and cholestanol increase down the core in the upper layer (Sections 1-4). H owever, extractable cholesterol (top three sections) shows the opposite trend relative to the two stanols. The increase of stanol and decrease of stenol with depth indicates that hydrogenation of stenol (Gaskell \& Eglinton, 1975) was occurring in the upper layer. 


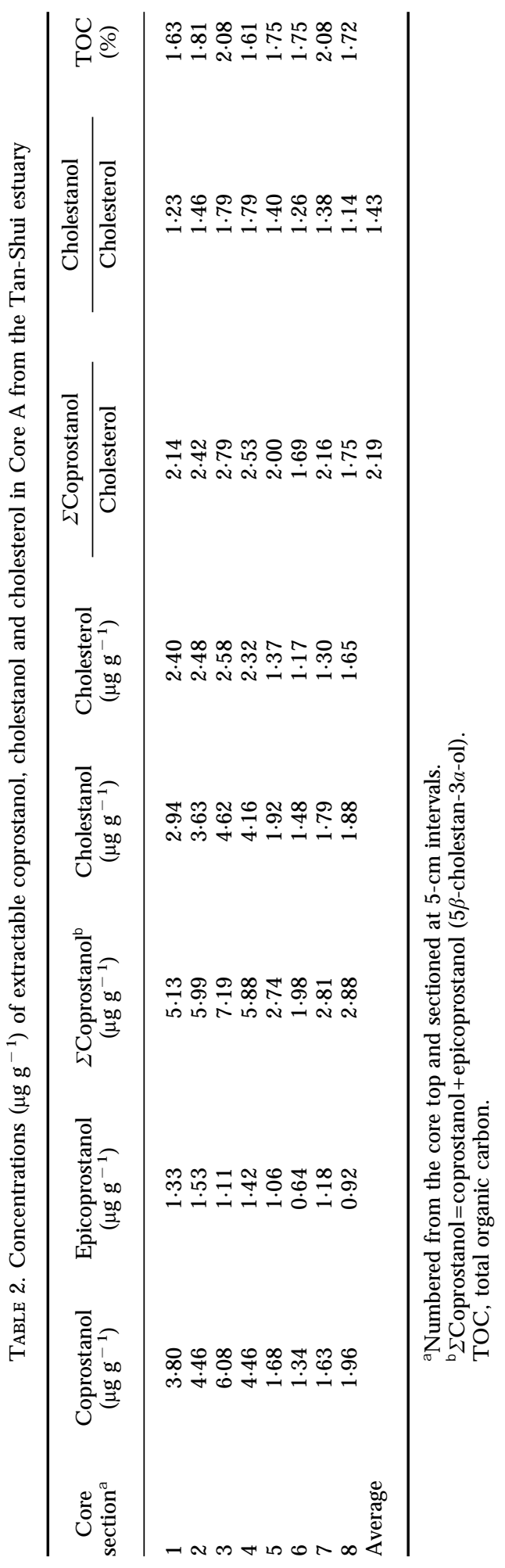




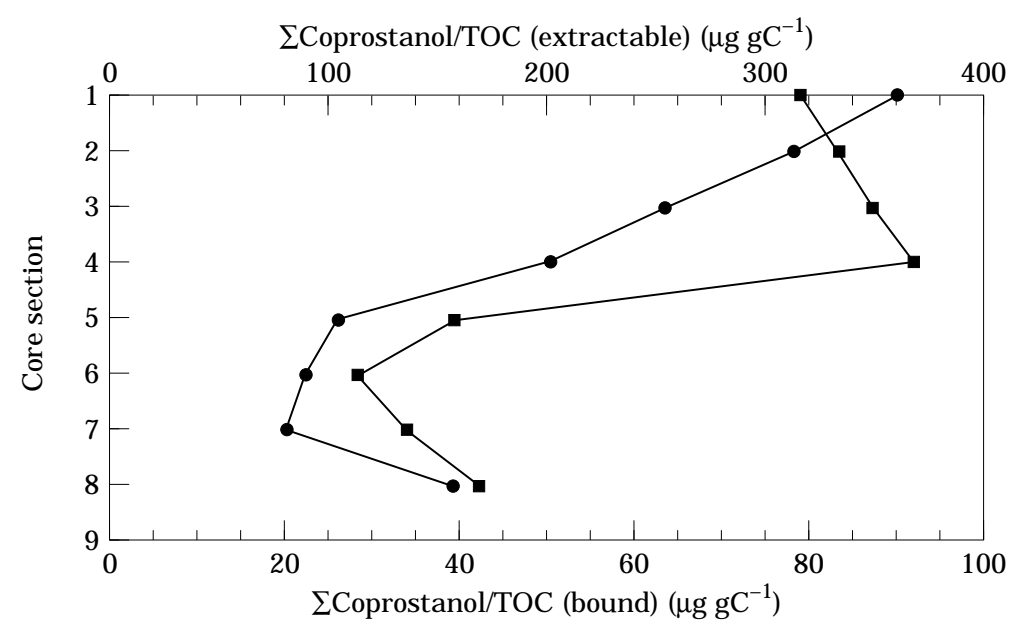

Figure 2. Depth profiles of $\Sigma$ coprostanol (normalized to total organic carbon) for Core A from the T an-Shui estuary. $\bullet$, Bound; $\mathbf{\square}$, extractable.

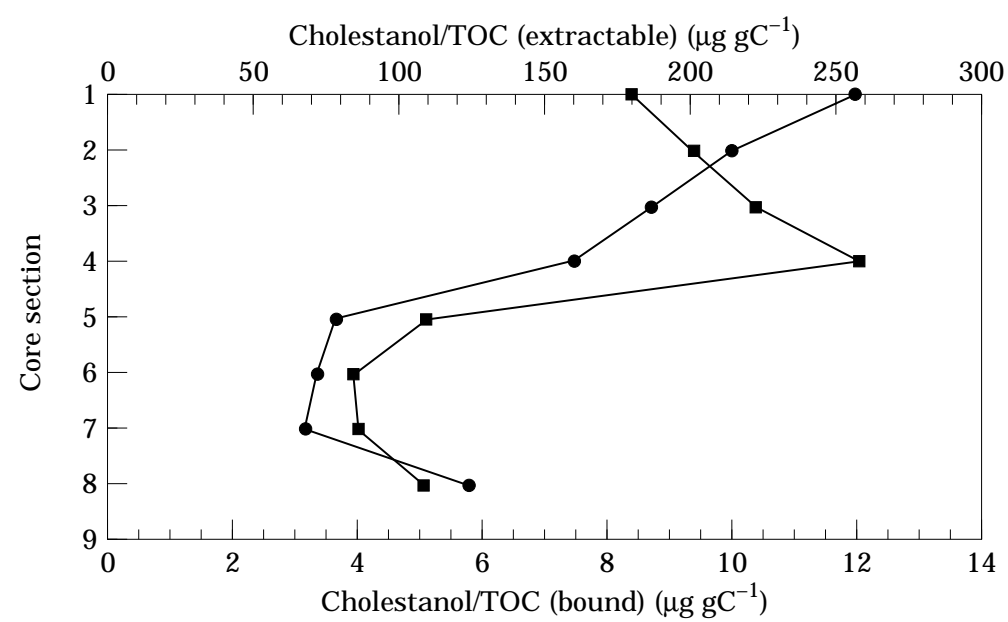

Figure 3. D epth profiles of cholestanol (normalized to total organic carbon) for C ore A from the T an-Shui estuary. $\bullet$, Bound; $\mathbf{\square}$, extractable.

This is thought to be attained by: (1) constant input sources; (2) constant degradation rates (or possibly no degradation); and (3) greater production than degradation of stanols. In the lower layer (Sections 5-8), however, extractable 5 coprostanol, cholestanol and cholesterol all exhibit a similar variation with depth but no depth trend. The reason for this remains unclear. H owever, one possible factor that might be associated with it is that the redox gradients (or redoxclines) in the sediments around Core A are generally in the top $15-25 \mathrm{~cm}$ (T able 1 ). Beyond the redox gradients, redox potentials stop dropping and fluctuate with depth. In other words, the strength of anoxicity in the lower layer stops increasing and is weakened, consequently affecting sterol hydrogenation.

Linear regression of extractable $\Sigma$ coprostanol and cholestanol vs. depth (using the mean depth of each core section) for the upper layer gives the following equations: 


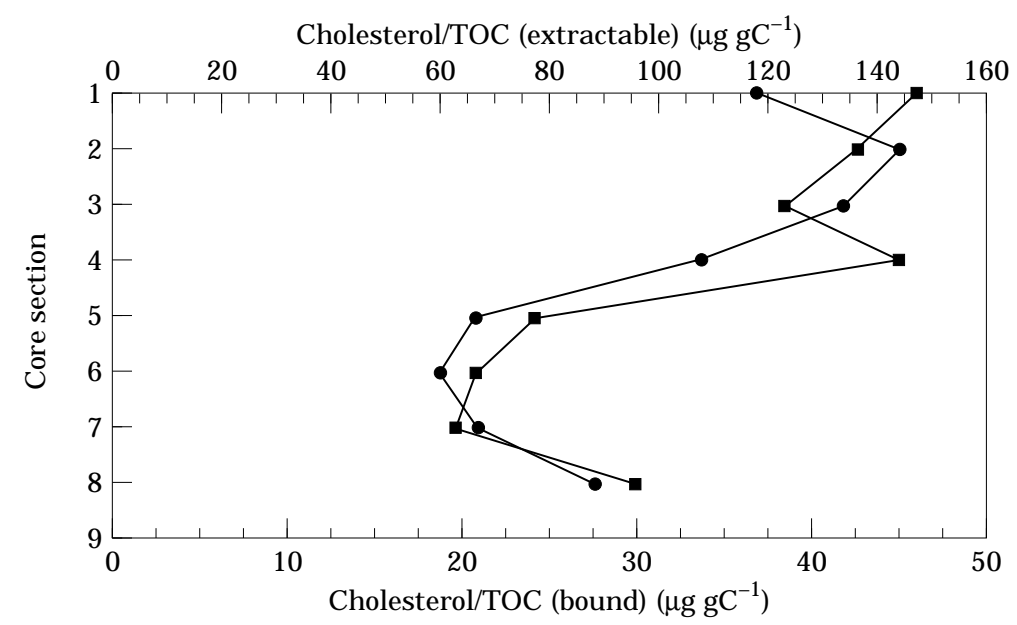

Figure 4. D epth profiles of cholesterol (normalized to total organic carbon) for C ore A from the Tan-Shui estuary. $\bullet$, Bound; $\mathbf{0}$, extractable.

$$
\begin{aligned}
& \Sigma \text { coprostanol } / \mathrm{T} \mathrm{OC}=3.3 \text { depth }+306 \quad(r=0.999) \\
& \text { cholestanol/T OC }=5 \cdot 1 \text { depth }+164 \quad(r=0.990)
\end{aligned}
$$

where $\Sigma$ coprostanol/T OC and cholestanol/T OC are in $\mu \mathrm{g} \mathrm{gC}^{-1}$ and depth is in $\mathrm{cm}$. It is interesting to note that the slope for cholestanol $(5 \cdot 1)$ is greater than that for $\Sigma$ coprostanol (3.3). This is attributed to the fact that the $5 a$ stanol is thermodynamically more stable than its $5 \beta$ epimer (Van Graas et al., 1982). Therefore, the sedimentary reduction process of cholesterol gives rise to stanol mixtures in which $5 a$ stanol predominates (Gaskell \& Eglinton, 1975; N ishimura \& Koyama, 1977; Boudou et al., 1986; Robinson et al., 1986).

Coprostanol is only found in the faeces of higher mammals and is nearly humanspecific (Walker et al., 1982), especially in urbanized estuaries where human waste predominates. $C$ holestanol is not a common constituent of most organisms but has been found in some living organisms ( $\mathrm{N}$ ishimura \& Koyama, 1977). Compared with these two stanols having relatively limited sources, cholesterol is quantitatively the most important sterol of animals ( $T$ issot \& Welte, 1978) and widespread in plant life (Volkman, 1986). The concentration of cholesterol in sediment depends on the amount of input sources during deposition; therefore, irregular variation with depth may result. The concentration of extractable cholesterol in Section 4 may result from a large input (Figure 4).

T able 3 presents the concentrations of bound sterols. In Figures 2 and 3, excluding the Section 8 data point, both bound $\Sigma$ coprostanol/T OC and cholestanol/T OC exhibit a decrease with core depth and no pronounced concentration change between Sections 4 and 5. It appears that bound stanols are not influenced markedly by the enhanced sewage input change. T he decreasing trend with depth might be ascribed to assimilation by bacteria and/or chemical decomposition. Lee et al. (1977) studying sterol diagenesis in recent sediments from Buzzards Bay found that extractable sterols decreased in concentration while bound sterols increased in concentration with depth. From this result, they inferred that a transformation between extractable and bound sterols 
T ABLE 3. Concentrations $\left(\mu \mathrm{g} \mathrm{g}^{-1}\right.$ ) of bound coprostanol, cholestanol and cholesterol

in Core A from the Tan-Shui estuary

\begin{tabular}{lccccc}
\hline $\begin{array}{l}\text { Core } \\
\text { section }\end{array}$ & $\begin{array}{c}\text { Coprostanol } \\
\left(\mu \mathrm{g} \mathrm{g}^{-1}\right)\end{array}$ & $\begin{array}{c}\text { Epicoprostanol } \\
\left(\mu \mathrm{g} \mathrm{g}^{-1}\right)\end{array}$ & $\begin{array}{c}\Sigma \text { Coprostanol } \\
\left(\mu \mathrm{g} \mathrm{g}^{-1}\right)\end{array}$ & $\begin{array}{c}\text { Cholestanol } \\
\left(\mu \mathrm{g} \mathrm{g}^{-1}\right)\end{array}$ & $\begin{array}{c}\text { Cholesterol } \\
\left(\mu \mathrm{g} \mathrm{g}^{-1}\right)\end{array}$ \\
\hline 1 & 1.24 & 0.22 & 1.46 & 0.19 & 0.61 \\
2 & 1.20 & 0.22 & 1.42 & 0.19 & 0.81 \\
3 & 1.11 & 0.21 & 1.32 & 0.18 & 0.87 \\
4 & 0.66 & 0.15 & 0.81 & 0.12 & 0.54 \\
5 & 0.35 & 0.10 & 0.45 & 0.065 & 0.36 \\
6 & 0.29 & 0.10 & 0.39 & 0.059 & 0.33 \\
7 & 0.28 & 0.13 & 0.41 & 0.066 & 0.44 \\
8 & 0.52 & 0.15 & 0.67 & 0.099 & 0.49 \\
\hline
\end{tabular}

T ABLE 4. Percent bound $\Sigma$ coprostanol, cholestanol and cholesterol in Core A from the T an-Shui estuary

\begin{tabular}{lccc}
\hline $\begin{array}{c}\text { Core } \\
\text { section }\end{array}$ & ECoprostanol & Cholestanol & Cholesterol \\
\hline 1 & 22 & $6 \cdot 1$ & 20 \\
2 & 19 & $5 \cdot 0$ & 25 \\
3 & 16 & $3 \cdot 8$ & 25 \\
4 & 12 & $2 \cdot 8$ & 19 \\
5 & 14 & $3 \cdot 3$ & 21 \\
6 & 16 & $3 \cdot 8$ & 22 \\
7 & 13 & $3 \cdot 6$ & 25 \\
8 & 19 & $5 \cdot 0$ & 23 \\
Average & 16 & $4 \cdot 2$ & 23 \\
\hline
\end{tabular}

appeared to be occurring over the entire core. However, it is worthy of note that their depth trends are the reverse of those found in the present study. The main cause of this difference is that the core was in a reducing environment in the present study. It is quite probable that extractable stanol formation rates greatly exceed sterol degradation rates.

Percent bound sterols are calculated as follows:

$$
\% \text { Bound }=[\text { Bound } /(\text { Extractable }+ \text { B ound })] \times 100
$$

The results are presented in T able 4 . It is noted that the averages of percent bound sterols are in the order, cholesterol $>\Sigma$ coprostanol>cholestanol. Before diagenesis, it is assumed that the three sterols have about the same percentage of bound fractions. Part of the extractable cholesterol is transformed into stanols during diagenesis resulting in an increase in percent bound cholesterol. At the same time, extractable coprostanol and cholestanol increased due to diagenesis, thus decreasing the percent bound stanol. As mentioned above, since there is less diagenetic coprostanol than diagenetic cholestanol, there is more percent bound $\Sigma$ coprostanol than percent bound cholestanol.

\section{Acknowledgements}

We are grateful to referees for constructive comments. This study was financially supported by the $\mathrm{N}$ ational Science $\mathrm{C}$ ouncil, Republic of $\mathrm{C}$ hina. 


\section{References}

Bartlett, P. D. 1987 Degradation of coprostanol in an experimental system. M arine Pollution Bulletin 18, 27-29.

Boudou, J. P., T richet, J., Robinson, N . \& Brassell, S. C. 1986 Lipid composition of a Recent Polynesian microbial mat sequence. O rganic $\mathrm{G}$ eochemistry 10, 705-709.

Brown, R. C. \& Wade, T. L. 1984 Sedimentary coprostanol and hydrocarbon distribution adjacent to a sewage outfall. W ater R esearch 18,621-632.

Gaskell, S. J. \& E glinton, G. 1975 Rapid hydrogenation of sterols in a contemporary lacustrine sediment. N ature 254, 209-211.

Gaudette, H. E., Flight, W. R., T oner, L. \& Folger, D. W. 1974 An inexpensive titration method for the determination of organic carbon in recent sediments. J ournal of Sedimentary Petrology 44, 249-253.

Goodfellow, R. M., Cardoso, J., Eglinton, G., Dawson, J. P. \& Best, G. A. 1977 A faecal sterol survey in the Clyde Estuary. M arine Pollution Bulletin 8, 272-276.

H atcher, P. G. \& M cG illivary, P. A. 1979 Sewage contamination in the N ew Y ork Bight. Coprostanol as an indicator. Environmental Science and Technology 13, 1225-1229.

Jasper, J. P. \& Gagosian, R. B. 1993 The relationship between sedimentary organic carbon isotopic composition and organic biomarker compound concentration. Geochimica Cosmochimica Acta 57, 167-186.

Jeng, W. L. \& H an, B. C. 1991 Coprostanol as an indicator of environmental pollution on the western coast of T aiwan. J ournal of the Chinese Environmental Protection Society (ROC) 14, 38-47.

LeBlanc, L. A., Latimer, J. S., Ellis, J. T . \& Quinn, J. G. 1992 T he geochemistry of coprostanol in waters and surface sediments from $\mathrm{N}$ arragansett Bay. Estuarine, Coastal and Shelf Science 34, 439-458.

L ee, C., G agosian, R. B. \& F arrington, J. W. 1977 Sterol diagenesis in recent sediments from Buzzards Bay, M assachusetts. G eochimica Cosmochimica A cta 41, 985-992.

M cC alley, D. V., Cooke, M. \& N ickless, G. 1980 Coprostanol in Severn Estuary sediments. Bulletin of Environmental Contamination and Toxicology 25, 374-381.

M cC alley, D. V., Cooke, M. \& Nickless, G. 1981 Effect of sewage treatment on faecal sterols. Water Research 15, 1019-1025.

M uller, G., K anazawa, A. \& T eshima, S. I. 1979 Sedimentary record of fecal pollution in part of Lake Constance by coprostanol determination. N aturwissenschaften 66, 520-522.

Nishimura, M. 1978 G eochemical characteristics of the high reduction zone of stenols in Suwa sediments and the environmental factors controlling the conversion of stenols into stanols. Geochemica Cosmochimica Acta, 42, 349-357.

$\mathrm{N}$ ishimura, M $19825 \beta$-isomers of stanols and stanones as potential markers of sedimentary organic quality and depositional paleoenvironments. Geochimica Cosmochimica A cta 46, 423-432.

N ishimura, M . \& K oyama, T. 1977 T he occurrence of stanols in various living organisms and the behavior of sterols in contemporary sediments. G eochimica Cosmochimica A cta 41, 379-385.

Readman, J. W., Preston, M. R. \& M antoura, R. F. C. 1986 An integrated technique to quantify sewage, oil and PAH pollution in estuarine and coastal environments. M arine Pollution Bulletin 17, 298-308.

Robinson, N ., Cranwell, P. A., Eglinton, G., Brassell, S. C., Sharp, C. L., Gophen, M . \& Pollingher, U. 1986 Lipid geochemistry of Lake K inneret. O rganic G eochemistry 10, 733-742.

Tissot, B. P. \& Welte, D. H. 1978 Petroleum Formation and O ccurrence. Springer-Verlag, Berlin, p. 41.

Van G raas, G., Baas, J. M. A., van de G raaf, B. \& de L eeuw, J. W. 1982 T heoretical organic geochemistry. I. The thermodynamic stability of several cholestane isomers calculated by molecular mechanics. G eochimica Cosmochimica A cta 46, 2399-2402.

Venkatesan, M . I. \& K aplan, I. R. 1990 Sedimentary coprostanol as an index of sewage addition in Santa M onica Basin, southern C alifornia. Environmental Science and Technology 24, 208-214.

Volkman, J. K. 1986 A review of sterol markers for marine and terrigenous organic matter. Organic G eochemistry 9, 83-99.

Walker, R. W., K un, C. K. \& Litsky, W. 1982 Coprostanol as an indicator of fecal pollution. CRC Critical Reviews in Environmental Control 12, 91-112.

Y de, W., D eWulf, E., D eM aeyer-Cleempoel, S. \& Quaghebeur, D. 1982 Coprostanol and bacterial indicators of fecal pollution in the Scheldt Estuary. Bulletin of Environmental Contamination and Toxicology 28, 129-134. 